\title{
Muralf
}

INTERNACIONAL

\section{O horizonte da justiça transicional no Uruguai The horizon of transitional justice in Uruguay}

\section{ANDRÉS DEL RÍO ROLDAN ${ }^{1}$}

Resumo: A investigação e o castigo às violações dos direitos humanos das ditaduras nos países da América Latina se tornaram uma questão inevitável para o fortalecimento e a consolidação das democracias da região. No presente trabalho, observaremos os principais eventos no processo de justiça transicional no Uruguai desde o governo de Jose Pepe Mujica até os dias de hoje (2010-2016). Analisaremos os principais eventos recentes observando a participação dos (e nos) tribunais no processo de luta pela memória, verdade e justiça. Examinaremos as novidades e desafios no horizonte da justiça transicional no Uruguai. O estudo tenta colaborar com o debate atual sobre os processos de revisão do passado violento na nossa região, desde a perspectiva da justiça transicional.

Palavras-chave: Justiça transicional; Lei de Caducidade; Ditadura; Suprema Corte de Justiça; Uruguai.

Abstract: The investigation and punishment for violations of the human rights of dictatorships in Latin America have become an unavoidable issue for the strengthening and consolidation of democracies in the region. In this paper, we will observe the major events in the transitional justice process in Uruguay since the government of Jose Pepe Mujica to the present day (2010-2016). We will review the main recent events observing the participation of (and in) the courts in the struggle for memory, truth and justice. We will examine the new challenges on the horizon of transitional justice in Uruguay. The study attempts to collaborate in the current debate about the violent past review processes in our region, from the perspective of transitional justice.

Keywords: Transitional Justice; Law Forfeiture; Dictatorship; Supreme Court; Uruguay.
Recebido em:

08 de Outubro de 2016

Received on:

October 08, 2016

Aceito em:

15 de Dezembro de 2016

Accepted on:

December 15, 2016

DOI: 10.12957/rmi.2016.25242

${ }^{1}$ Doutor em Ciências Políticas pelo Instituto de Estudos Sociais e Políticos da Universidade do Estado do Rio de Janeiro (IESP/UERJ). Professor Adjunto de Ciência Política do Bacharelado em Políticas Públicas da Universidade Federal Fluminense (UFF), no Instituto de Educação de Angra dos Reis (IEAR). Endereço Profissional: Av. do Trabalhador, 342, Verolme, Angra dos Reis - RJ, CEP: 23914-165. E-mail: andresdelrio@id.uff.br 
"Si me dieran a elegir, yo elegiría esta salud de saber que estamos muy enfermos, esta dicha de andar tan infelices". Juan Gelman ${ }^{2}$

\section{Uma Aproximação}

Conciliar as dores de um passado marcado pelas violações aos direitos humanos como acontecido no Cone Sul nas ditaduras dos anos 70 e 80 não é uma tarefa simples. As ditaduras da região trouxeram anos de horrores, a partir da Doutrina de Segurança Nacional, abraçada pela Operação Condor $^{3}$, unindo-nos na dor do terrorismo de Estado.

Os 12 anos que a ditadura permaneceu no Uruguai (1973-1985), o terrorismo de Estado se tornou um período que ainda está em processo de compreensão, revisão e disputa. A principal dimensão repressiva do regime ditatorial uruguaio foi a reclusão massiva e prolongada. Com um universo de quase 6.000 presos políticos entre 1973 e 1984, o método carcerário se relacionou diretamente com a aplicação generalizada e sistemática de tortura aos detentos. Esta

\footnotetext{
${ }^{2}$ Parte do poema "El juego en que andamos", do Livro do mesmo nome editado em Buenos Aires, 1959.

3 Coordenação das cúpulas dos governos ditatoriais da Argentina, Brasil, Bolívia, Chile, Uruguai e Paraguai para a luta contra a sedição e a defesa nacional. Uma rede transacional secreta de operações de inteligências e contra insurgência dos regimes militares desses países.
}

marca carcerária caracteriza este período uruguaio como uma ditadura mais do tipo policial que militar (Rico 2009, p.151).

As democracias onde ocorreram esse tipo de regime abordaram o tema das justiças transicionais com diferentes soluções de acordo com as particularidades de cada país. Cada nação enfrenta seu passado violento segundo suas possibilidades, estruturas institucionais, movimentos sociais e políticos. Assim, um frágil equilíbrio vai se gestando a partir dos diferentes setores e da diversidade de demandas de cada cenário nacional. No processo, a reconciliação não tem o mesmo significado para todos os integrantes da sociedade. O Poder Judiciário tem um papel fundamental na materialização da justiça e punição, mas nem sempre é parte dos setores que desejam revisar o passado, ou tem uma atitude ativa em respeito à busca da verdade e punição. A justiça constitui mais um espaço de luta política e de negociação na reconciliação e reconstrução, podendo ser um ator de importância na revisão, ou um limite na busca pela verdade.

De uma trajetória intermitente e sem uma ruptura substancial, hoje em dia não é possível entender a justiça transicional sem observar os movimentos dos (e nos) tribunais, a 


\section{Muralf}

INTERNACIONAL
Mural Internacional

V. 7 |N. 1

JAN-JUN 2016 atividade existente a partir das organizações de direitos humanos, base principal da luta pela revisão do passado no Uruguai. No presente trabalho, de forma breve, descreveremos os últimos e principais eventos, desafios e obstáculos do processo de justiça transicional uruguaio, salientando a dimensão da justiça.

\section{A justiça transicional}

Sem entrar no debate teórico, mas sim como uma breve apresentação conceitual, a Justiça Transicional (JT) emerge como resposta concreta às violações sistemáticas aos direitos humanos no passado, não democrático, e traumático. A partir de uma definição suficientemente ampla para abarcar as diversas modalidades de JT que se pretenda: de forma simples Paul Van Zyl indica:

"O objetivo da justiça transicional implica em processar os perpetradores, revelar a verdade sobre crimes passados, fornecer reparações às vítimas, reformar as instituições perpetradoras de abuso e promover a reconciliação. $\mathrm{O}$ que foi mencionado anteriormente exige um conjunto inclusivo de estratégias formuladas para enfrentar o passado assim como para olhar o futuro a fim de evitar o reaparecimento do conflito e das violações". (Van Zyl 2009, p. 32).

Neste sentido o mesmo autor salienta:
“(...) as estratégias da justiça transicional são arquitetadas em contextos nos quais a paz é frágil ou os perpetradores conservam um poder real, deve-se equilibrar cuidadosamente as exigências da justiça e a realidade do que pode ser efetuado a curto, médio e longo prazo". (Ibid., p. 33)

Assim, a justiça transicional tem quatro dimensões primordiais: a reparação às vítimas, a busca da verdade e a construção da memória, a reforma das instituições do Estado, e o restabelecimento da igualdade dos indivíduos ante a lei. Segundo a International Center for Transitional Justice (ICTJ): "nenhuma medida isolada é tão eficaz como todas elas combinadas" (Olsen et al 2009, p.166).

No presente trabalho realizaremos uma análise da trajetória recente dos principais eventos existentes em Uruguai, desde a perspectiva da Justiça Transicional, tendo especial atenção à dimensão da justiça no processo de luta pela memória, verdade e justiça.

\section{José Pepe Mujica ao Poder (2010 a 2015)}

A movimentação nos tribunais nos anos anteriores e durante o mandato de José Pepe Mujica gerou algumas condenações notórias: em fevereiro de 2010 foram processados e condenados dois ex-ditadores Juan Maria Bordaberry e Gregório Alvarez. O 
primeiro condenado a 30 anos de prisão por encabeçar o golpe de 1973, além de uma série de assassinatos; e o segundo, condenado a 25 anos de prisão pelos 37 assassinatos agravados. Ainda em abril de 2010, o civil e ex-chanceler Juan Carlos Blanco foi condenado a 20 anos de prisão pelo assassinato de Elena Quinteros. Em junho de 2011, Bordaberry e Blanco também seriam condenados por ordenar e coordenar os homicídios dos políticos da oposição Zelmar Michelini e Hector Gutierrez Ruiz, e dos ex-guerrilheiros Rosário Barredo e Willliam Whitelaw. Em maio de 2013, houve a primeira condenação de um oficial militar em atividade, o General Miguel Dalmao, pelo assassinato de Nibia Salbasagaray (Burt et al, 2015; Lessa 2016, p. 6; Skaar 2011, p. 146).

Outro evento notório da época foi o caso Gelman. Exilado em 1975 pelos militares, o escritor Juan Gelman teve o filho assassinado, a nora desaparecida e a neta sequestrada pelo regime. Assim que soube que tinha uma neta, em 1978, acionou os governos argentino e uruguaio, que se recusaram a investigar o caso. No primeiro mandato de Julio María Sanguinetti, presidente do Uruguai entre 1985 e 1990, foi aprovada a Ley de Caducidad de la Pretensión Punitiva del Estado, mais conhecida como Ley de Caducidad, que evitou a investigação e judicialização de casos envolvendo militares e policiais que cometeram crimes contra os direitos humanos no período do regime. Gelman, em 2000, encontra sua neta e em 2006 acionam a Corte Interamericana de Direitos Humanos (CIDH).

Somente em 24 de fevereiro de 2011 a Corte publicou a sentença:

"Dada su manifiesta
incompatibilidad con la
Convención Americana, las
disposiciones de la Ley de
Caducidad que impiden la
investigación y sanción de graves
violaciones de derechos humanos
carecen de efectos jurídicos y, en
consecuencia, no pueden seguir
representando un obstáculo para la
investigación de los hechos del
presente caso y la identificación y
el castigo de los responsables, ni
pueden tener igual o similar
impacto respecto de otros casos de
graves violaciones de derechos
humanos consagrados en la
Convención Americana que
puedan haber ocurrido en el
Uruguay". (CIDH 2011, p. 68).

A partir da sentença, diversas organizações de direitos humanos passaram a ter um propósito duplo: por um lado, assegurar o cumprimento das obrigações impostas pela $\mathrm{CIDH}$; por outro, consolidar o esforço de unidade permanente daqueles atores sociais que deviam ter um papel fundamental no processo de justiça (Olivera Alfaro 2016, p. 10). 


\section{Muralf}

INTERNACIONAL
Mural Internacional

V. 7 | N. 1

JAN-JUN 2016
Como parte do processo de cumprimento da sentença da CIDH, em 30 de junho de 2011, Mujica aprovou a resolução 323/2011 que revogou administrativamente as resoluções adotadas pelos governos anteriores (1985-2005) que ampararam, sob a Ley de Caducidad, distintas denúncias sobre violações aos direitos humanos cometidas na ditadura. Assim, o sistema de justiça seria o encarregado exclusivo de completar a tarefa de desarquivar causas, investigar os eventos e sancionar os responsáveis (Olivera Alfaro 2016, p. 26).

A partir daí, foram removidos os obstáculos para a ação penal em 88 casos que tinham sido arquivados entre 1986 e 2005, e que foram remetidos aos tribunais para sua investigação. Porém, a Ley de Caducidad, ainda em vigor, poderia bloquear os novos casos apresentados na justiça (Burt et al 2015, p. 17). Nesse cenário, novos problemas apareceram, não (só) de caráter jurídico, mas da incapacidade material e da inexistência de ferramentas institucionais e administrativas para garantir a eficácia do processo de justiça.

É bom lembrar que outra barreira da Ley de Caducidad era que parte das violações aos direitos humanos cometidos na ditadura foi considerada como delitos comuns, e estavam sujeitas à prescrição a partir da data limite de $1^{\circ}$ de novembro de $2011^{4}$. Desta forma, se fecharia a possibilidade de apresentar novas denúncias e iniciar processos futuros sobre delitos que não eram considerados como de lesa humanidade.

Porém, de forma rápida, o Executivo elaborou e a Câmara de Representantes aprovou a lei 18.831 , restabelecendo a pretensão punitiva do Estado ante os delitos cometidos durante o período ditatorial, considerando-os como crime de lesa humanidade. No seu artigo n.2 estabeleceu que não se computaria prazo algum, processual, prescrição ou de caducidade. No seu terceiro artigo declarou que os delitos serão considerados de lesa humanidade de acordo com os tratados internacionais.

O novo cenário institucional permitiu que entre 2011 e 2012 uma importante quantidade de processos chegassem aos tribunais. Segundo as estatísticas do Observatório Luz Ibarburu foram aproximadamente 80 causas em cada ano (OLI, 2016b).

Em março de 2012, em representação do Estado uruguaio e em cumprimento do disposto pela sentença da Corte IDH

\footnotetext{
${ }^{4}$ Se contabiliza desde o primeiro de março de 1985 , data formal do retorno democrático.
} 
de 24 de fevereiro de 2011, o presidente Mujica pronunciou:

\begin{abstract}
"El Estado uruguayo reconoce que en el pasado se cometieron en el país acciones violatorias de los derechos humanos. (...) se llevó adelante una política sistemática de represión. (...) Y el desarrollo de esa Doctrina de la Seguridad Nacional, el Estado Uruguayo integró el llamado Plan Cóndor”.
\end{abstract}

No âmbito judicial, porém, houve alguns retrocessos; em fevereiro de 2013, a Suprema Corte de Justiça (SCJ) tomou uma medida que foi extremamente criticada. Através da resolução 70/2013 determinou o translado da magistrada Mariana Mota de um tribunal penal a um civil. Da mesma forma que tinha acontecido com o Reyes e outros ${ }^{5}$, o translado de Mota foi uma sanção a uma magistrada que tinha em suas mãos aproximadamente 50 casos de violações aos direitos humanos. As críticas se tornaram mobilização, comunicados e protestos das organizações de defesa dos direitos humanos e outros setores (Rico et al 2014, p.137-152).

Neste processo tumultuado, a Suprema Corte de Justiça ainda voltaria a ser notícia: dias depois do translado da magistrada Mota, a SCJ declarou inconstitucionais os artigos 2 e 3 da

\footnotetext{
${ }^{5}$ Alberto Reyes, Estela Jubette, Alejando Recarey e Mirtha Guianze sofreram pressões e em alguns casos traslados.
}

recente lei $18.831^{6}$. Os argumentos principais da sentença salientaram que ao estabelecer que não se computariam os prazos de prescrição já transcorridos e por dispor de forma retroativa que à natureza original do tipo penal, se adicionando ainda o caráter de crimes de lesa humanidade e provocando como consequências sua impossibilidade de extinção, fragilizam ostensivamente o princípio de irretroatividade da lei penal (Rico et al 2014, p.155). Da mesma maneira a SCJ expediu em outras sentenças ${ }^{7}$.

O comportamento da justiça despertou a preocupação da Alta Comissionada das Nações Unidas, já que abria o caminho para o fechamento das investigações em curso, violentando o direito das vítimas à verdade, justiça e reparação (Pillay, 2013). Na mesma linha se expressou a Comissão Interamericana de Direito Humanos sobre a sentença: "es una muestra de que no existe seguridad jurídica alguna en Uruguay sobre la eliminación de los efectos de la Ley de Caducidad" (CIDH-OEA, 2013). Segundo o Pablo Greiff (2013), Relator Especial da ONU, em visita ao Uruguai, em outubro de 2013, declarou: “( ...) nada parece amenazar más las posibilidades de progreso en el área de

\footnotetext{
${ }^{6}$ A sentença foi votada em maioria dos integrantes da SCJ, mas em dissidência o juiz Ricardo Pérez Manrique.

7 Sentenças da SCJ n.152, n.186, n.212.
} 


\section{Muralf}

INTERNACIONAL
Mural Internacional

V. 7 | N. 1

JAN-JUN 2016 la justicia que decisiones recientes de la Suprema Corte de Justicia". Palermo (2014, p.175) indica que a sentença demonstra que a nova lei 18.831 não parece ter sido um acerto legislativo, senão um novo e apressado antídoto à questionada Ley de Caducidad para solucionar um aspecto pontual do processo de justiça de transicional.

Em março de 2013, a Corte Interamericana de Direitos Humanos publicou a supervisão do cumprimento da sentença do Caso Gelman. Nela estabelece claramente que o Estado do Uruguai: “(...) no puede invocar disposiciones del derecho constitucional $u$ otros aspectos del derecho interno para justificar una falta de cumplimiento de la Sentencia" (CIDH 2013, p. 31). Assim, os argumentos da Suprema Corte de Justiça que apontaram para a irretroatividade da lei penal e os limites de não considerar como crimes de lesa humanidade não estavam de acordo com a convenção.

O retrocesso protagonizado pela Suprema Corte de Justiça de Uruguai trariam consequências nos casos já reabertos. Em abril de 2013, por exemplo, a magistrada Fanny Canessa determinou o arquivamento por prescrição do caso Sosa Bustos.
Tabaré Vázquez: os labirintos da justiça. (2015-)

Ao final do mandato de Pepe Mujica e início do governo de Tabaré Vasquez, a Suprema Corte de Justiça contrariando as posições anteriores, passou a adotar uma postura diferente ao considerar os crimes da ditadura - antes aceitos como delitos comuns - como crimes de lesa humanidade (Lessa 2016, p. 7). Porém, não se pode afirmar que se trate de uma tendência consolidada, já que essa Suprema Corte de justiça foi integrada com outros membros, ante ausência dos titulares (Guianze 2016, p. 8).

Em uma polêmica declaração, e sintomática da negação do estado da judicialização das causas das violações aos direitos humanos durante a ditadura, o presidente da Suprema Corte de Justiça Chediak (2015) afirmou que: "el Poder Judicial de Uruguay ha sido particularmente exitoso en la persecución de quienes cometieron las flagrantes violaciones a los derechos humanos en la dictadura".

Contrariando essa declaração, segundo a própria base de dados da Equipe Jurídica do "Observatorio Luz Ibarburu" (EJOLI) sobre a judicialização dos crimes da ditadura em Uruguai, há 192 casos de desaparições forçadas, porém apenas processos abertos. Dos 124 homicídios 
registrados, 17 vítimas conseguiram acionar efetivamente a justiça. Até hoje não existe nenhum processo pelo delito de tortura e marginal os casos por violência sexual (Ejoli 2015, p. 5).

Agrega-se a estes dados, de acordo com o último informe atualizado do Observatório Luz Ibarburu (OLI, 2016b), o fato de existirem 284 denúncias judiciais por crimes de lesa humanidade e somente seis delas (ou seja, o $2 \%$ do total) tem sentença. Cerca de $63 \%, 180$ causas, se encontram numa situação de paralisia e finalmente, 66 delas, ou $23 \%$ do total, foram arquivadas por diferentes motivos. Há ainda causas judiciais no exterior, principalmente na Argentina e um na Itália (Rico 2015, p. 20). Revela-se assim que os dados do Observatório são suficientes para contradizer os ditos do Chediak. A sociedade civil ainda está à espera de resultados e sempre mobilizada.

Com relação aos arquivos, apesar de alguns avanços ${ }^{8}$, os diversos setores das Forças Armadas continuam ocultando documentos, e não abrem as informações sobre os detentos desaparecidos, tornando-se um forte limite aos direitos à memória e à

\footnotetext{
${ }^{8}$ No mês de outubro 2015, na causa do falecido Coronel Castiglioni, se encontraram aproximadamente 60 caixas com documentos da época.
}

verdade. Os países da região ainda se encontram muito longe de ter consolidado o rumo como o que se pratica na experiência internacional sobre arquivos repressivos (Caetano 2011, p. 29). Falta ainda regulamentar a lei de aceso à informação, e superar obstáculos jurídicos que dificultam a entrega de documentos (Guianze 2016, p. 6; Alves Nogueira \& Paiva Carvalho 2016, p. 171; Chargoñia 2011, p. 174).

Uma manifestação do sentimento dessa impunidade é força presente das Marchas do Silêncio, que ocorre anualmente em 20 de maio. Em 2015 o lema foi "Basta de impunidade já: verdade e justiça". No ano de 2016, a bandeira foi: "Ellos en nosotros. Contra la impunidad de ayer y de hoy. Verdady Justicia", mobilizando uma enorme quantidade de pessoas no centro de Montevideo. Um dia anterior ao protesto, numa conferência de imprensa, a organização de mães e familiares de detentos desaparecidos desenhou de forma crua a atualidade da JT em Uruguai:

\footnotetext{
"Ninguno há hecho las transformaciones ni ha tomado las decisiones necesarias para dar un vuelco total en este tema. Las causas judiciales se empantanan (algunas llevan hasta 30 años tramitándose), la búsqueda de restos no avanzan y las amenazas, intimidaciones, robos, a las
} 


\section{Muralf}

INTERNACIONAL

personas que trabajan en el tema, han sido una constante" (Desaparecidos, 2016).

Dentro das novidades institucionais, a partir do decreto131/2015, em maio de 2015, se constituiu o Grupo de Trabalho pela Verdade e Justiça integrado por figuras reconhecidas na luta contra a impunidade $^{9}$. A Secretaria de Direitos Humanos para o passado recente é seu suporte funcional e administrativo. $\mathrm{O}$ propósito essencial do grupo é investigar os crimes de lesa humanidade cometidos pelos agentes do estado ou pessoas que tivessem contado com a autorização, ou apoio deste, dentro ou fora das fronteiras, no marco da atuação ilegítima do estado e do terrorismo de estado. Segundo notícias oficiais do Grupo, novas medidas estão sendo implementadas. Foram apresentadas propostas para os próximos dois anos e se fechou recentemente um convênio com a Universidade da República para recavar testemunhas de forma massiva com propósitos judiciais e investigativos (Presidencia, 2016b). Há uma crítica, porém, que com amplíssimos objetivos, o Grupo de Trabalho não tem competências especificas para o cumprimento das suas atribuições, tem

9 O Grupo de Trabalho está integrado por Macarena Gelman, Felipe Michelini, Emilia Carlevaro, Mario cayota, Ademar Olivera, Pedro Sciofky e Susana Andrade.
Mural Internacional

V. 7 |N. 1

JAN-JUN 2016 pouca coordenação com outros atores, e não tem apresentado os avanços realizados, nem informes sobre as suas atividades desempenhadas até hoje (Mota 2016, p. 6; Guianze 2016, p. 5).

Outra inovação do período foi à criação da Unidade especializada em Direitos Humanos pela resolução 002/2015 de setembro de 2015. A unidade é dirigida pelo Fiscal adjunto da Suprema Corte de Justiça $^{10}$. Ela tem por competência realizar os assessoramentos, análises, coordenações, capacitação e difusão de informação que resultem necessários para facilitar a atuação eficiente e efetiva dos representantes da Promotoria Geral da Nação em aqueles processos judiciais relativos às graves violações aos direitos humanos cometidas durante a ditadura (1973-1985). Segundo o Observatório (OLI 2016a, p. 193) a unidade está: "subaproveitada, por desconhecimento de seu papel e das possibilidades que pode oferecer como auxiliar da justiça”.

Finalmente, em junho de 2016, o Senado aprovou o projeto para adiantar a entrada em vigor do novo código de processo penal. Desta forma, o novo código começará a reger a partir de

\footnotetext{
10 A unidade é dirigida pelo Promotor Ariel Cancela e integrada pela promotora Ana María Tellechea, pela promotora Stella Llorente e a promotora Adscripta Carolina Rico (Presidencia, 2016a).
} 
julho de 2017, e pela primeira vez dará participação às vítimas de delitos. Parte do debate foi a transferência aos promotores da competência de dirigir as investigações penais, hoje conduzidas pelos juízes (Alves Nogueira \& Paiva Carvalho 2016, p. 172). Mas é a atuação da sociedade civil até os dias de hoje que segue assumindo a função que seria do Estado. A sociedade civil continua sendo o principal auxiliar de justiça (OLI 2016a, p. 191).

Todas estas inovações, importantes mas ainda embrionárias, abrem novos desafios e interrogações na justiça transicional em Uruguai. $\mathrm{E}$ essas interrogações se multiplicam com o novo cenário regional de retrocesso de direitos sociais, de administrações conservadoras e de implementação de políticas neoliberais. Uma volta ao conservadorismo que pode alterar o horizonte. No caso argentino, na administração de Mauricio Macri, existem alguns retrocessos institucionais nesta área especifica, gerando preocupação nas organizações de direitos humanos desse país e na região ${ }^{11}$. No caso Brasil, o debate parece

\footnotetext{
${ }^{11}$ Existe um desmantelamento, total ou parcial, de áreas que investigavam sobre a responsabilidade ou cumplicidades com o terrorismo de Estado, paralisando outras áreas, reorganização do pessoal, e/ou orçamentos não totalmente executados ou mal executados. Exemplo: a redução à metade do pessoal da Direção de Direitos Humanos do Ministério de Segurança, e o desmantelamento do Grupo
}

ter saído da agenda com a ruptura (golpe) institucional de 2016 liderado por Michel Temer: não existe seguimento nem cumprimento das recomendações realizadas pela Comissão da Verdade. Além disso, houve nomeações controversas como as realizadas sem consulta à sociedade e com históricos problemáticos na Comissão de Anistia, e em cargos de relevância para o tema, como o caso de Alexandre de Moraes como Ministro de Justiça, causando consequências na dinâmica interinstitucional ${ }^{12}$.

\section{Um horizonte incerto}

Os países da região estão em pleno processo de revisão do passado violento recente. A justiça transicional na maioria dos países da América Latina tem hoje em dia duas características: é cada vez mais judicializada e cada vez mais internacionalizada. Mas são a qualidade e as características dessa

Especial de Relevamento Documental que auxiliava à justiça (Pagina 12, 2016).

${ }^{12} \mathrm{O}$ ministro da Justiça, Alexandre de Moraes, nomeou 19 novos conselheiros para a Comissão de Anistia. Um deles, foi o Paulo Lopo Saraiva. Ele foi sargento do Exército e serviu à instituição durante o período da ditadura militar no Brasil. Além disso, o ministro da Justiça também dispensou dos cargos de conselheiros da Comissão de Anistia Ana Maria Guedes, Carolina Melo, José Carlos Moreira Filho, Manoel de Almeida, Márcia Moraes, Prudente Mello e Virginius França. Pediram para deixar a comissão os exconselheiros: Aline Santos, Caroline Proner, Narciso Patriota, Nilmário Miranda e Roberta Baggio (Globo, 2016). 


\section{Muralf}

INTERNACIONAL

judicialização e a capacidade institucional para internalizar as novidades internacionais que são fundamentais para compreender cada caso de estudo. Cada país revisa seu passado violento e traumático, a sua forma e velocidade, segundo suas estruturas, instituições e movimentos sociais. Uruguai demonstrou que é um caso único de como se confrontou com seu passado violento e tomou um caminho próprio, diferente de outros países do Cone Sul.

No Uruguai não se constituíram tribunais especiais para o tema, nem tribunais de competências exclusivas para tramitar esses processos, nem se capacitou magistrados e operadores de justiça para considerar as especificidades dos processos de características excepcionais. É importante salientar a falta de conhecimento (ou vontade) e da aplicação do direito internacional dos direitos humanos por parte dos magistrados (Lessa 2016, p. 7). Existem incapacidades, tanto de matérias como de ferramentas institucionais e administrativas para a eficácia do processo de justiça (OLI 2016a, p. 191). A lentidão com que tramitam as causas é mais um obstáculo neste processo (Ejoli, 2015). Dados os atuais recursos com que conta o sistema de justiça, sem a participação e o aporte ativo das
Mural Internacional

V. 7 | N. 1

JAN-JUN 2016

vítimas, denunciantes, familiares e organizações de direitos humanos, pouco se pode avançar (Prats 2010, p. 236; Chargoñia 2011, p. 171).

Além disso, foram excluídos de toda investigação os ilícitos econômicos durante a ditadura, cometidos por agentes do Estado em prejuízo de particulares. Também não se tem procurado determinar a responsabilidade civil em comissão de delitos analisados, circunscrevendo o campo investigativo aos militares individualizados em cada causa. Foram marginais as denúncias aceitas sobre as numerosas violências sexuais sofridas, nem se denunciou a tortura, sendo ela o mecanismo sistemático de tratamentos de detentos e presos. (Mota 2016, p. 3 5; Chargoñia 2011, p.170). O tempo todo se batalhou para que as denúncias relativas aos crimes cometidos durante $o$ terrorismo de estado tramitassem como se fossem denúncias de delitos comuns. E a qualificação destes delitos como comuns permite aplicação do instituto de prescrição que determina a clausura de causas. Neste cenário, é fácil se beneficiar com a prisão domiciliar que está expressamente excluída para quem foi processado por delitos de lesa humanidade, qualidade que não tem sido atribuída aos crimes. Agrega-se a isso as dificuldades existentes com relação aos arquivos da ditadura: quanto 
mais passe o tempo, mais árdua será a tarefa de seu tratamento (Guianze 2016, p. 5; Caetano 2011, p. 29). No âmbito internacional, existem ainda processos em andamento que geram expectativas e alimentam esperanças não satisfeitas pelos tribunais locais.

A atual e incerta postura da Suprema Corte de Justiça coloca o Uruguai numa situação de radical oposição com a jurisprudência majoritária, não só na região, mas na produção internacional. Como indica Sikkin (2015), se um país quer realmente conseguir resultados e quer tornar-se uma democracia sólida, deve realizar juízos. Neste sentido, existiu neste processo de justiça transicional uma continuidade que foi mudando gradualmente, timidamente, mas não existiu uma ruptura. A lei de caducidade ainda está em vigor depois de 30 anos de vida. A trajetória da JT parece ter entrado numa fase nova, com uma perna na arena na dimensão da justiça. Mas o cenário é complexo, o processo está em construção. Como indica o Informe Uruguai Nunca Mais (1989: 4) sobre o pasado violento recente: “...rescatar esa historia es aprender una lección, sacar conclusiones para mirar con los ojos sin vergüenza hacia el futuro".

\section{Bibliografia}

Alves Nogueira, A. R.; Paiva Carvalho, C. (2016). "Uruguay - Panorama da justiça de transição em 2015”, in: Paiva Carvalho, C.; Nogueira Guimarães, J. O.; Guerra, M. P. (2016), Justicia de transición en América Latina: panorama 2015. Brasília: Ministério da Justiça, Comissão de Anistia, Rede Latino-Americana de Justiça de Transição (RLAJT).

Burt, Jo-Marie; Fried, G.; Lessa, F. (2015). "La sociedad civil y el resurgir de la lucha contra la impunidad en Uruguay (1986-2014)”. Alternativas, n.5.

Caetano, G. (2011). "Los archivos represivos en los procesos de justicia transicional: una cuestión de derechos". Perfiles Latinoamericanos 37, Enero-junio.

Chargoñia, P. (2011). "Avances, retrocesos y desafíos en la lucha judicial contra la impunidad", in: Fried, G., Lessa, F. (compiladoras). (2011), Luchas contra la impunidad Uruguay 1985-2011. Ediciones Trilce. 


\section{Muralf}

INTERNACIONAL

Mural Internacional

V. 7 | N. 1

JAN-JUN 2016

Chediak, J. (2015). "El estilo tradicional del Poder Judicial es muy parecido al de Tabaré Vázquez". BRECHA, 27 marzo, 2015.

Comisión interamericana de derechos Humanos (CIDH-OEA). (2013). Comunicado de Prensa emitido al culminar el 147 Período de Sesiones. 5 de abril de 2013.

Corte interamericana de derechos humanos - CIDH. (2011). Caso Gelman vs. Uruguay. Sentencia del a Corte Interamericana del 24 de febrero de 2011. (Fondo y Reparaciones).

Corte interamericana de derechos humanos - CIDH. (2013). Resolución de la Corte Interamericana de Derechos Humanos de 20 de marzo de 2013 Caso Gelman vs. Uruguay. Supervisión de cumplimiento de sentencia.

Desaparecidos - Madres y Familiares de detenidos desaparecidos. (2016). "21 marcha del Silencio". Conferencia de Prensa, 19 de mayo 2016. Url: http://bit.ly/2bF27F0.

Equipo Juridico del Observatorio Luz Ibarburu - EJOLI. (2015). Informe Anual 2015 del Observatorio Luz Ibarburu. Documento-Diciembre. Montevideo, Uruguay.

Globo. (2016). "Ministro da Justiça nomeia 19 novos conselheiros da Comissão de Anistia". 03 de setembro de 2016. Url: https://goo.gl/Mtx9z9 . [Acesso em: 08 Jul. 2016]

Greiff, P. G. (2013). "Relator especial de ONU presentó observaciones preliminares sobre su visita oficial a Uruguay". Prensa ONU, 4 de octubre de 2013, Url: http://goo.gl/AxmHol . [Acesso em: 08 Jul. 2016]

Guianze, M. (2016). “La impunidad más allá de la Ley de Caducidad. Construcción de un marco jurídico nacional de derechos humanos vs. persistencia de la cultura de impunidad". ILCEA [En ligne], 26 | 2016, Url: http://goo.gl/WrDQiC. [Acesso em: 28 Jul. 2016]

Lessa, F. (2016). "¿Justicia o impunidad? Cuentas pendientes a treinta años del retorno a la democracia”. ILCEA [Online], 26 | 2016, Url: http://bit.ly/2bZ0gyZ . [Acesso em: 28 Jul. 2016] 
Mota, M. (2016). "Los difíciles caminos de la justicia en derechos humanos en Uruguay”. ILCEA [En ligne], 26 | 2016, URL: http://bit.ly/2b3AZ3P . [Acesso em: 20 Jul. 2016]

Observatório luz IBARBURU - OLI. (2016a). "Ditadura e transição democrática no Uruguai”, in: Paiva Carvalho, C.; Nogueira Guimarães, J. O.; Guerra, M. P. (2016), Justicia de transición en América Latina: panorama 2015. Brasília: Ministério da Justiça, Comissão de Anistia, Rede Latino-Americana de Justiça de Transição (RLAJT).

Observatório luz ibarburu - OLI. (2016b). "Reporte de estado de causas - agosto 2016”. Uruguay. Online LINK: http://goo.gl/S3wQBR . [Acesso em: 10 Ago. 2016]

Olivera Alfaro, R. (2016). "Memoria, verdad y justicia en Uruguay: la gestión del pasado en un escenario de luces y sombras". ILCEA [En ligne], 26 | 2016, Url: http://bit.ly/2bv87n7. [Acesso em: 15 Jul. 2016]

Olsen, T., Payne, L. y Reiter, A. (2009). "Equilibrando julgamentos e Anistias na América Latina: Perspectivas comparativa e Teórica". Revista Anistia Política e Justiça de Transição, (2), 152-175. Brasil.

Página 12. (2016). "Del hecho al dicho". Página 12, Sección El país. Argentina: Pagina 12. 15 de agosto de 2016. Url: http://bit.ly/2bgW1Oj. [Acesso em: 20 Ago. 2016]

Palermo, P. G. (2014). "El proceso de justicia de transición en Uruguay”, in: TOSI, Giuseppe (Organizador). Justiça de transição: direito à justiça, à memória e à verdade. João Pessoa: Editora da UFPB.

Pillay, N. (2013). "Alta comisionada de ONU para Derechos Humanos preocupada por decisión de la SCJ". El Observador, 24 de febrero 2013, Uruguay. Url: http://tinyurl.com/z3rx9oq [Acesso em: 10 Jul. 2016]

Prats, M. (2010). "Uruguay", in: DPLF - Fundación para el Debido Proceso Legal. (2010), Las víctimas y la justicia transicional. Estan cumpliendo los estados americanos con los estándares internacionales? DPLF - Fundación para el Debido Proceso Legal. Washington, DC 


\section{Muralf}

INTERNACIONAL

Mural Internacional

V. 7 | N. 1

JAN-JUN 2016

Presidencia. (2016a). "Policías y fiscales se capacitan para investigar crímenes de lesa humanidad". Comunicación, 20 de julio 2016. Url: http://tinyurl.com/zh7hwyf . [Acesso em: 20 Jul. 2016]

. (2016b). "Grupo por Verdad y Justicia firma convenio con Universidad de la República para recabar más testimonios". Comunicación, Uruguay, 16 de agosto 2016. Url: https://goo.gl/xobw0M . [Acesso em: 20 Ago. 2016]

Rico, A. et al. (2014). Cómo votaron los partidos en el plebiscito contra la caducidad en 2009 y la historia contra la impunidad 2006-2013. Ediciones Trilce. Montevideo, Uruguay.

Rico, A. (2009). "Practicas estatales criminales en dictadura y relaciones sociales degradadas en Democracia, Uruguay", in: Feierstein, Daniel Compilador. (2009), Terrorismo de estado y genocidio en América Latina. Buenos Aires: Prometeo Libros - PNUD.

. (2015). "Introducción”. Actualización de la Investigación histórica sobre detenidos desaparecidos (1971-1982). Investigación histórica sobre asesinados políticos (1973-1985). Presidencia de la República, secretaría de derechos humanos para el pasado reciente e Universidad de la República, Montevideo.

Serpaj - Servicio Paz y Justicia. (1989). Uruguay Nunca Más. Informe sobre la violación a los derechos humanos (1972-1985). Montevideo, diciembre.

Sikkin, K. (2015). "Entrevista a Kathryn Sikkink". LADI, Revista Latinoamericana de Derecho Internacional, N.2, http://bit.ly/2aZz41V [Acesso em: 08 Jun. 2016]

Skaar, E. (2011). "Impunidad versus responsabilidad jurídica: el rol de la Ley de Caducidad en Uruguay", in: Fried, G., Lessa, F. (compiladoras). (2011), Luchas contra la impunidad Uruguay 1985-2011. Ediciones Trilce.

Van Zyl, P. (2009). "Promovendo a justiça transicional em sociedades pós-conflito". Revista Anistia Política e Justiça de Transição, (1), 32-55. Brasil. 